\title{
Thinking Analogy in Solving Indirect Analogy Problems based on Information Processing Theory
}

\author{
*Kristayulita Kristayulita, Lalu Sucipto \\ Tadris Matematika, Fakultas Tarbiyah dan Keguruan, UIN Mataram. Jl. Gajah Mada No.100 \\ Jempong Baru Mataram, 83125 Indonesia \\ *Corresponding Author e-mail: kristayulita@uinmataram.ac.id \\ Received: December 2021; Revised: January 2022; Published: January 2022
}

\begin{abstract}
Cognitive ability in solving analogy problems really needs the right information processing. The core cognitive process in analogy thinking occurs when students make a mapping between the target problem and the source problem. This research aims to describe analogical thinking in solving indirect analogy problems based on information processing theory. The method usesd in this research is qualitative descriptive. The subject in this study were third and fifth-semester students of the Mathematics Tadris Program FTK UIN Mataram. Instruments are source problems and target problems use indefinite integral problems in the Integral Calculus course. Data analysis is used by using triangulation of methods and data sources. The results showed that there were $51.06 \%$ able to solve the target problem where students are able to recall long-term memory information related to solving source problems that have similarities to solving target problems. Source problem-solving information taken from long-term memory is used by students in solving target problems in short-term memory. The processing of information in short-term memory depends on the mapping process with previous information in long-term memory. Therefore, as a mathematics teacher, he is able to emphasize certain materials which are initial knowledge to study further material.
\end{abstract}

Keywords: Analogical Thinking, Indirect Analogy Problems, Information Processing Theory

How to Cite: Kristayulita, K., \& Sucipto, L. (2022). Thinking Analogy in Solving Indirect Analogy Problems based on Information Processing Theory. Prisma Sains : Jurnal Pengkajian Ilmu dan Pembelajaran Matematika dan IPA IKIP Mataram, 10(1), 93-103. doi:https://doi.org/10.33394/j-ps.v10i1.4574

https://doi.org/10.33394/j-ps.v10i1.4574

Copyright $\odot$ 2022, Kristayulita \& Sucipto This is an open-access article under the CC-BY License.

\section{INTRODUCTION}

Thinking is a process of obtaining information, processing information, storing information, and recalling information that is regulated by the brain (Slavin, 2006). Ruggiero \& Vincent said that thinking is mental activity to help formulate a problem, make a decision, or fulfill a curiosity (Ruggiero \& Vincent, 2011). This shows that thinking occurs when someone is faced with a problem. Solso stated that thinking is a process of generating new mental representations through information transformation which involves complex interactions between mental attributes. Mental attributes are referred to as abstraction, judgment, imagination, problem-solving, and logic (Robert L. Solso et al., 2005). For example, when reading a book, the information received goes through various stages from sensory processing to memory, the information is transformed to produce new information or new knowledge.

Thinking is a series of processes starting with the entry of information, processing information to forming a thinking scheme whose process is dynamic and can be described by a process or path. Reheat shows that information processing occurs because of the interaction between a person's external and internal conditions. External conditions are the external environment that affects a person in the learning process. While the internal conditions are conditions within a person that are needed to achieve learning outcomes (Reheat, 2014). One 
of the thinking processes in achieving the learning outcomes needed by students to learn mathematics is to think by analogy.

Analogy is a similarity (Polya, 2004). Furthermore, Polya said that analogy is a sort of similarity, similar objects agree with each other in some aspect, and analogous objects agree in certain relations of their respective parts. Orgill \& Bodner stated that analogy is a comparison between two elements that are not really similar or completely different which is used to introduce a transfer system of relations between elements in an analog source that is familiar to a foreign target element. (Orgill \& Bodner, 2006). The same thing is also stated by Falkenhainer, et al that analogy is a knowledge mapping between two objects so that the relationship system that holds one of the objects in the analog source also has between objects in the analogy target. (Falkenhainer et al., 1989). While analogy thinking is a type of thinking that is used to conclude new information about other new cases based on previously known cases (Gentner, 1983). Analogy thinking is the process of transferring knowledge from a known situation (source problem) to a new situation (target problem) with the aim of increasing certain understandings (Trench et al., 2009). Analogous thinking in problem solving involves using a known problem structure (called the source problem) to help solve a new, related problem (called the target problem). Indirect analogy thinking processes are representation, structuring, mapping, applying, and verifying (K. Kristayulita, 2021). In problem solving with analogy thinking, a cognitive process is needed in mapping the source problem with the target problem. Cognition processes occur in a person as in processing information.

Information processing theory is a cognitive theory related to learning theory that explains the processing, storage, and recall of knowledge from the brain (Slavin, 2006, 2008). Slavin explained that information processing in the human mind is a process that starts from external stimuli receiving information until a response is generated through several stages of information processing. (Slavin, 2006, 2008). This theory explains how a person acquires some information and can be remembered for a long time. Information is processed and stored in three stages, namely: sensory registers, short-term memory, and long-term memory. In the sensory register stage, the visual recording receives a lot of information from the senses and stores it in a short time (Slavin, 2006, 2008). If there is information that is not stored in the sensing register, the information will quickly be lost. Information processing at the sensory register stage is very important because it is a requirement to be able to process further information, so that students' defense of new information received is very necessary. (Panjaitan, 2013). A person's interpretation of a stimulus can be said to be perceived. Perception of an indirect stimulus or stimulus such as a receiving stimulus, because perception is influenced by mental status, experience, knowledge, motivation, and many other factors. (Slavin, 2006, 2008). Information that is noticed and perceived by a person will be forwarded to the second stage of the memory system, namely short-term memory or working memory.

Short-term memory is a limited information storage system that lasts only a few seconds (Slavin, 2006, 2008). Short-term memory relates to what a person thinks when receiving stimuli from the environment. Information that enters short-term memory gradually disappears when the information is no longer needed (Panjaitan, 2013). If the information in short-term memory continues to be used, then over time the information will be passed on to the next stage, namely long-term memory. Therefore, one way to store information in shortterm memory is to think about the information or express it continuously.

Long-term memory is part of the third-stage memory system where information will be stored for a long time (Slavin, 2006, 2008). Meanwhile, Panjaitan showed that long-term memory is relatively permanent memory storage, which can store information even though the information is no longer needed. Information stored in long-term memory will be organized into certain forms of knowledge structures called schemas. Schemas group 
information elements according to how the information will be used, so schemas facilitate access to information in the future when it will be used (Panjaitan, 2013).

Research related to analogy thinking is still discussing the components of analogy thinking (Kristayulita et al., 2019; K. Kristayulita, 2021; Ruppert, 2013; Sternberg, 1977), problem solving with analogy thinking(Gentner \& Loewenstein, 2002; Trench et al., 2009), and analogy thinking schemes (K. Kristayulita et al., 2018; Kristayulita Kristayulita et al., 2017, 2020). Thinking analogy in solving problems has not been studied using information processing theory. Information processing theory used in the study of Disturbances experienced by students occur when students recall information in long-term memory to be used to solve problems in short-term memory when solving combination problems (Sukoriyanto, 2018). Therefore, this study describes the analogy thinking process of students in solving indirect analogy problems based on information processing theory. When students are given a mathematical problem related to an analogy problem, the problem is seen as an external stimulus. The analogy problem faced by students is in the form of a target problem entering the sensory register. If the target problem does not get the attention of students, then the target problem will be forgotten by students. If the target problem gets the students' attention, then the target problem will be transferred to the second stage of the memory system, namely short-term memory. In the second stage of the memory system, students in solving the target problem they are facing need information in the form of a schema that is stored in long-term memory in the form of solving the source problem by retrieving information in the form of a schema that is stored in long-term memory and has similarities with the target problem being faced.

\section{METHOD}

This type of research is qualitative research with a qualitative descriptive approach. One of the characteristics of qualitative research is that the research process is always dynamic, all stages of the research process may change after the researcher enters the field and begins to collect data. For example, the individuals studied and the locations visited are also subject to change at any time (Creswell \& Cheryl, 2016). This study reveals the process of indirect analogy reasoning in solving mathematical problems. The type of analogy used in this study is an analogy problem consisting of a source problem and a target problem. The source problem used is the definite integral problem. While the target problem is a complex integral problem. In this research, the researcher makes a picture, examines sentences/words, reports a detailed view of the research subject's view, and conducts a study in a natural situation. This study aims to describe the indirect analogy thinking process in solving indefinite integral problems.

There are 141 students of the Tadris Mathematics Study Program for the academic year 2021/2022 who have taken integral calculus courses. Subjects depicted by analogous thinking process data using information processing theory as many as 1 student representing. The research instrument is the researcher, but there are auxiliary instruments in the form of source problems and target problems related to integral calculus material. This instrument has been validated by 3 experts in mathematics and mathematics education. All validators said the instrument was feasible to use.

Table 1. Indirect Analogy Problem (Purcell et al., 2010)

Source problem

Determine the integral of

$$
\int x d x
$$

Determine the integral of

$$
\int 2 x \sqrt{x^{2}+1} d x
$$

The research steps in revealing indirect analogy thinking processes in solving indefinite integral problems require the following stages: 1) Give indirect analogy problems; 2) Grouping students into fourth categories, namely correct-correct, correct-false, false-correct, 
and false-false; 3) Conduct interviews; 4) Analyzing the data; 5) Data validation; 6) Concluding the research.

\section{RESULTS AND DISCUSSION}

Respondents in this study were students in the third and fifth semesters of Mathematics Education, FTK UIN Mataram. There are 85 students who have taken the Integral Calculus course in the third semester and 81 students in the fifth semester with a total of 166 students. Respondents who participated in the study were 141 students with details in Table 2.

Table 2. Distribution of Data Tests for source problems and target problems for Semester III and $\mathrm{V}$ students

\begin{tabular}{ccccc}
\hline No & Source problem & Target problem & Semester III & Semester V \\
\hline 1 & Correct & Correct & $\mathbf{6 1}$ & $\mathbf{3 6}$ \\
2 & Correct & False & $\mathbf{6}$ & $\mathbf{1 3}$ \\
3 & False & Correct & $\mathbf{5}$ & $\mathbf{8}$ \\
4 & False & False & $\mathbf{4}$ & $\mathbf{6}$ \\
\hline \multicolumn{7}{c}{ Sub-Total } & & $\mathbf{7 6}$ & $\mathbf{6 5}$ \\
\hline Total & & & $\mathbf{1 4 1}$ & \\
\hline
\end{tabular}

Furthermore, students are grouped based on their analogy thinking done by students in solving source problems with target problems correctly. Among of students who answered the source problem and the target problem correctly from all categories (correct-correct, correct-false, false-correct, and false-false) were 97 students. More details can be seen in Table 3.

Table 3. Data Distribution of Student Analogy Thinking in solving indirect analogy problems in semester III and V

\begin{tabular}{|c|c|c|c|c|}
\hline No & Source problem & Target problem & Yes (Analogy Thinking) & No \\
\hline 1 & Correct & Correct & 71 & 26 \\
\hline \multicolumn{3}{|c|}{ Total } & \multicolumn{2}{|l|}{97} \\
\hline
\end{tabular}

The analogy thinking process using information processing theory is taken by 1 student as a representation from 71 students. The subject chosen to describe the analogous thinking process based on information processing theory is a student with the initials subject ST. Subject STs were given an indirect analogy problem related to indefinite integrals. Indirect analogy problems consist of source problems and target problems. The source problem has easy and simple characteristics while the target problem has difficult and complex characteristics, and the target problem is a modification of the source problem. The source problem is solved first before the target problem is given. In solving source problems, subject ST start by understanding and identifying source problems. When reading the source problem, the subject understands the problem correctly. Subject STs immediately knew that the problem was to determine the value of the indefinite integral of $\sqrt{x}$. Subject ST start by changing to $\sqrt{x}$ Becomes $x^{\frac{1}{2}}$. The integral formula is used by subject ST in determining the value of an indefinite integral. Subject ST derives the value of the indefinite integral from the integral $\sqrt{x}$ is $\frac{2}{3} x \cdot \sqrt{x}$. This is in accordance with the following excerpts from the interview with the subject of ST and Figure 1.

Q : How do you determine the integral value?

ST: Change the root of $x$ to $x$ to the power of $1 / 2$

$\mathrm{Q}$ : After going through these steps, what do you do?

ST: Using the integral formula. So it becomes 1 per $1 / 2$ plus $1 x$ to the power of $1 / 2$ plus 1.

Q : After that what do you do next? 
ST: Simplify the operation so that the result is like this (pointing $\frac{2}{3} x \sqrt{x}+C$ ).

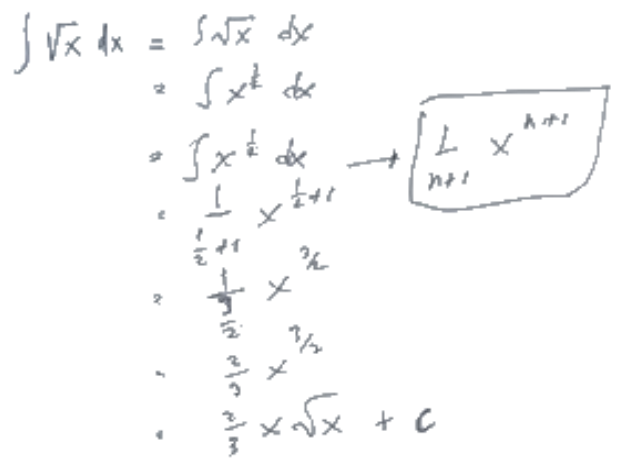

Figure 1. Work Results on Source Problems from Subject ST

Subject ST can solve the source problem because it is easy and familiar. English states that the source problem has the characteristics that it is given before the target problem, in the form of easy and medium problems, and can help solve the target problem or as preknowledge in the target problem (English, 1999).

Next, the subject solves the target problem. ST solves the problem $\int 2 x \sqrt{x^{2}+1} d x$ (target problem). First ST performs a representation of the target problem by assuming $t=x^{2}+1$, then ST reduces the equation to $d t=2 x d x$ and converts it to $d x=\frac{d t}{2 x}$. Representation Results on Target Problems from subject ST can see Figure 2 and the following interview results.

Q : What do you know about this question?

ST: what is known from this matter.... Find the indefinite integral of two $x$ root $x$ square plus $1 d x\left(\int 2 x \sqrt{x^{2}+1} d x\right)$

$\mathrm{Q}$ : Can you solve this problem?

ST: Yes.

Q : How?

ST: First, let $\mathrm{t}$ be equal to $\mathrm{x}$ squared plus $11\left(t=x^{2}+1\right)$. Then it is lowered with respect to $x$ to become dt equals $2 x d x \quad(d t=2 x d x)$. Next we write $d x$ equals $d t$ per $2 x$. (pointing $d x=\frac{d t}{2 x}$ ).

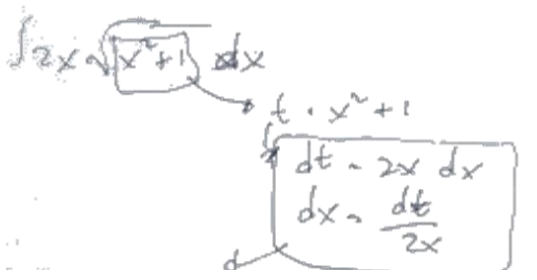

Figure 2. Representation Work Results on Target Problems from Subject ST

Then ST substitutes $t=x^{2}+1$ and $d x=\frac{d t}{2 x}$ to the indefinite integral $\int 2 x \sqrt{x^{2}+1} d x$ so that we get $\int 2 x t^{\frac{1}{2}} \frac{d t}{2 x}$. ST integral by putting the number 2 in front of the integral and separating $\frac{d t}{2 x}=\frac{d t}{x} \times \frac{1}{2}$ so that it becomes $2 \int x t^{\frac{1}{2}} \frac{d t}{x} \times \frac{1}{2}$, the subject puts the number $\frac{1}{2}$ in front of the integral so that it becomes $2 \times \frac{1}{2} \int x t^{\frac{1}{2}} \frac{d t}{x}$, followed by operating $2 \times \frac{1}{2}=1$ and $x \times \frac{d t}{x}=d t$ so that we get $\int t^{\frac{1}{2}} d t$. From the results obtained, ST finds a new indefinite integral (new target problem). Subject ST performs the structuring process on the new target problem by identifying indeterminate integrals that are different from the previous one. 
Structuring Work Results on Target Problems from subject ST can see Figure 3 and the following interview results.

Q : What integral is obtained?

$\mathrm{ST}$ : Integral root $t$ to the power of $1 / 2 d t$

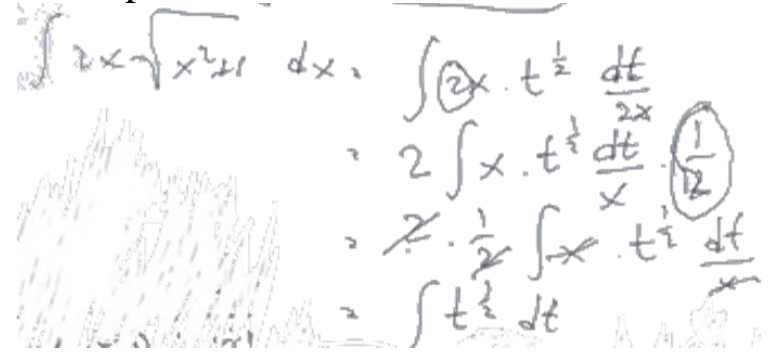

Figure 3. Structuring Work Results on Target Problems from Subject ST

In the process of representation and structuring, subject ST receives information by reading the given target problem, then the information is entered into the sensory register. According to Slavin, the first component of the memory system encountered by incoming information is sensory recording (Arciniegas et al., 1999; Hasson et al., 2015; Slavin, 2006, 2008). Students carry out reading activities by using their sense of sight to record the information they see. The information collected is based on the results of identifying the problem of determining the modified indefinite integral.

When information enters the sensory register, the attention process occurs in the Subject ST. Solso, et al stated that the concentration of mind in reading the question (target problem) carefully and carefully showed that both students paid attention to the information obtained so that it could be understood and remembered (R. L. Solso et al., 2008; Robert L. Solso et al., 2005; Wolfe \& Horowitz, 2017). With the attention of subject ST, they are able to identify the given target problem, so that they know what information is known and what information is asked. Prinz in Gurbin said that attention involves selecting some information for further processing (Gurbin, 2015). New information needs to have some meaning for the student, information will not survive if it is not meaningful to the student. According to Prinz in Gurbin, by paying attention to new information, the information may be connected with existing knowledge (Gurbin, 2015). According to Gagne, an individual's ability to identify a given problem is influenced by the experience and knowledge of the individual (Gagne, 1985). According to Gagne, an individual's ability to identify a given problem is influenced by the experience and knowledge of the individual $t=x^{2}+1$, perform the differential of the equation $t$ to $x$ obtained $d x=\frac{d t}{2 x}$.

Subject ST have a perception in solving a given problem after identifying known information from the target problem. Subject ST perception in solving the target problem by way of substitution. Then subject ST realized the perception in short-term memory (STM). The first step when realizing perception in STM, subject ST performs rehearsal by rewriting the information that has been given to the target problem. In addition, subject ST also retrieval (call back) knowledge of the formula for the volume of a block in long-term memory (LTM). Subject ST substituting for example $t=x^{2}+1$, perform the differential of the equation $u$ to $x$ obtained $d x=\frac{d t}{2 x}$ on the target problem so that the integral of $t^{\frac{1}{2}}$.

Subject ST pays attention to the form of the new target problem with the form of the previous source problem. ST says that solving the new target problem can be solved by means of solving the source problem. This means that subject ST does the mapping process. Mapping Work Results on Target Problems from subject ST can see Figure 4 and the following interview results.

Q : How did you solve the problem?

ST: Same before with this one (shows the previous question) 


\section{$\int t^{\prime 2} d t$}

Figure 4. Mapping Work Results on Target Problems from Subject ST

Subject ST gives a perception of the integral obtained which is the result of substitution on the target problem. Subject ST has the idea that the integral he gets is an equation similar to the previous source problem. Because subjects remember the source problem that has been done before. According to Gust, et al said that students will identify the source problem to be associated with the target problem (Gust et al., 2008). Furthermore, Gagne said that experience and knowledge stored in LTM can affect one's perception of the given stimulus (Gagne, 1985). Knowledge and experience that have been obtained and stored in LTM, can help in solving problems. A person's perception depends on how much the person has studied the stimulus as a result of previous learning. Subject ST has a target problem image formed like the previous source problem. This is because the two subjects remember the source problems that have been solved previously.

Subject ST retrieval the concepts needed to solve the target problem from LTM after doing perception, then realize it by applying to Subject ST STM. According to Gurbin, STM combines new information from the environment with previously known things stored in LTM in solving problems and what a person is thinking and consciously storing in STM. (Gurbin, 2015). When the cognitive process occurs, students often experience errors. Students retrieve the information needed by writing down their knowledge and trying to relate it to the information they receive. When solving problems, students will relate the situations in the problem to the knowledge and experience that students have previously (Heuer \& Sanders, 2016; Vidulich et al., 2010; Wickens, 1991; Wijaya et al., 2014). There is a process of remembering by students on various materials and questions that have been studied and matching them with the problems at hand.

Subject ST performs retrieval of the indefinite integral concept of $\sqrt{u}$. To solve the integral obtained in the target problem, the two subjects used the concept of the indefinite integral of $\mathrm{x}$. This means that there is a relationship between the source problem and the target problem being faced. It can be said that there is a harmonious relationship between the source problem and the target problem by identifying the parts of the relevant domain (Gentner, 1983; Gentner \& Loewenstein, 2002; Gust et al., 2008). Subject STs identify the relevant dominant part in the analogy relationship, do it systematically, and use the same solution steps.

And then ST does the applying process by solving the new target problem with the understanding that ST has so that it is obtained to solve $\int t^{\frac{1}{2}} d t=\frac{1}{\frac{1}{2}+1} t^{\frac{1}{2}+1}=\frac{1}{\frac{3}{2}} t^{\frac{3}{2}}+C=$ $\frac{2}{3} t^{\frac{3}{2}}+C$. Applying Work Results on Target Problems from ST can see Figure 5 and the following interview results.

Q : How did you solve the problem?

ST: Same before with this one (shows the previous question)

Q : After that what do you do?

ST: This is an indefinite integral, so we use the integral formula so that 1 is divided by half plus $1\left(\frac{1}{\frac{1}{2}+1}\right)$ and $t$ is to the power of half plus $1\left(t^{\frac{1}{2}+1}\right)$. then it becomes 1 divided by 3 by $2\left(\frac{1}{\frac{3}{2}}\right) \mathrm{u}$ to the power of 3 by $2\left(t^{\frac{3}{2}}\right)$. 


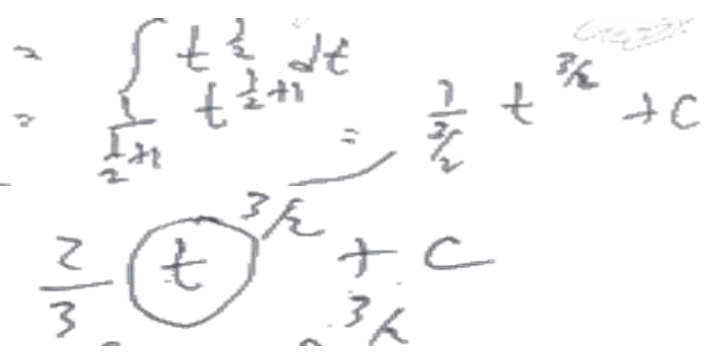

Figure 5. Applying Work Results on Target Problems from Subject ST

In the applying process, subject ST performs a retrieval of the indefinite integral solution of $\sqrt{u}$ sas was done in the source problem. The next step, subject ST performs a retrieval to determine the indefinite integral of $\sqrt{u}$ by using the integral formula so that we get $\frac{2}{3} u \cdot \sqrt{u}$. Subject ST knows how to solve the indefinite integral obtained in the target problem using a similar method to solving the previous source problem. Gentner \& Loewenstein said that there are 3 factors that influence mapping, namely relevance, systematic, and adaptation (Gentner \& Loewenstein, 2002).

And then subject ST performs the verifying process by substituting the equation $t=$ $x^{2}+1$ ke $\frac{2}{3} t^{\frac{3}{2}}+C$, so we get $\frac{2}{3}\left(x^{2}+1\right) \sqrt{\left(x^{2}+1\right)}+C$. Verifying Work Results on Target Problems from subject ST can see Figure 6 and the following interview results.

Q: once you find the integral of this (pointing to $\int t^{\frac{1}{2}} d t$ ). how did you solve it?

ST: oh.... I substituted $t=x^{2}+1$ into this (pointing $\frac{2}{3} t^{\frac{3}{2}}$ ). We know that $t=x^{2}+1 \ldots$ is added to $\frac{2}{3} t^{\frac{3}{2}}$ so that it becomes $\frac{2}{3}\left(x^{2}+1\right)^{\frac{3}{2}}+C$. So $\frac{2}{3}\left(x^{2}+1\right) \sqrt{\left(x^{2}+1\right)}+C$.

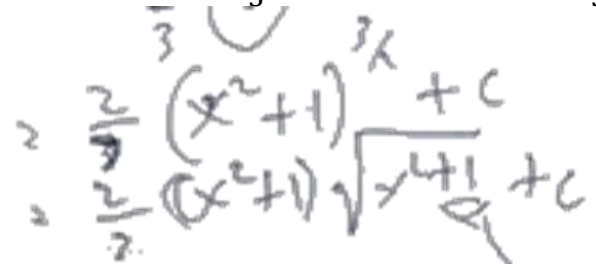

Figure 6. Verifying Work Results on Target Problems from Subject ST

In the verifying process, subject ST obtains the answer from solving the indefinite integral on the target problem. Almost subjects really understand the solutions that must be obtained from the problems at hand. And then almost subject rehearsed the answers obtained based on questions from the source problem. According to Santrock, conscious rehearsal of information increases the duration of the information (Santrock, 2009). This means that the subjects can correctly determine the answer to the target problem.

The process of connecting the target problem with the source problem has been carried out by the subject and understands that the target problem solving process has similarities with the source problem. Both subjects can perform arithmetic operations in determining the solution of the indefinite integral on the target problem. Students re-store in LTM the information they have after the STM process, both information that has just been obtained or information obtained from the results of recall which is called encoding.(R. L. Solso et al., 2008; Robert L. Solso et al., 2005). Gurbin said that encoding is merging new information into existing memory. This means that students can do encoding if students can explain the answers they get (Gurbin, 2015). Even though the answer to the target problem is not correct, the problem solving process is still stored in its long-term memory.

The results obtained by ST in solving the target problem are correct. Almost subjects did the representation, structuring, mapping, applying, and verifying correctly. Almost subjects think analogy in solving the source problem with the target problem. ST thinks the 
analogy is illustrated during the target problem solving process. This means that almost subjects think analogously in solving the target problem with problem solving procedures.

\section{CONCLUSION}

Students in solving target problems are able to recall long-term memory information related to source problem solving procedures which are similar to target problem solving procedures. Information on source problem solving procedures taken from long-term memory is used by students in solving target problems in short-term memory. Processing of information in short-term memory depends on the mapping process with previous information in long-term memory.

\section{RECOMMENDATION}

In integral learning activities, lecturers must always emphasize students to always remember all the information needed in solving problems that can be solved easily. Furthermore, lecturers need to emphasize certain materials that are related to the next material. This is done to make it easier for students to understand more complex material.

\section{ACKNOWLEDGMENT}

Thank you to the Institute for Research and Community Service (LP2M) UIN Mataram for providing the opportunity for research with funding from DIPA 2021.

\section{REFERENCES}

Arciniegas, D., Adler, L., Topkoff, J., Cawthra, E., Filley, C. M., \& Reite, M. (1999). Attention and memory dysfunction after traumatic brain injury: Cholinergic mechanisms, sensory gating, and a hypothesis for further investigation. Brain Injury, 13(1), 1-13. https://doi.org/10.1080/026990599121827

Creswell, J. W., \& Cheryl, N. P. (2016). Qualitative inquiry and research design: Choosing among five approaches. Sage publications.

English, L. D. (1999). Reasoning by analogy: a fundamental process in children's mathematical learning. In L. V. Stiff \& F. R. Curcio (Eds.), Developing mathematical reasoning in grades $K-12$ (pp. 22-36). Reston, VA: NCTM.

Falkenhainer, B., Forbus, K., \& Gentner, D. (1989). The Structure-Mapping Engine: Algorithm and Examples. Artificial Intelligence, 41, 1-63. https://www.sciencedirect.com/science/article/pii/0004370289900775

Gagne, R. M. (1985). The Condition of Learning and Theory of Instruction. Rinehart and Witnston, Inc.

Gentner, D. (1983). Structure-mapping: A theoretical framework for analogy. Cognitive Science, 7(2), 155-170. https://doi.org/10.1016/S0364-0213(83)80009-3

Gentner, D., \& Loewenstein, J. (2002). Relational Language and Relational Thought." Language, Literacy, and Cognitive Development: The Development and Consequences of Symbolic Communication.

Gurbin, T. (2015). Enlivening The Machinist Perspective: Humanising The Information Processing Theory With Social And Cultural Influences. Procedia - Social and Behavioral Sciences, 197(February), 2331-2338. https://doi.org/10.1016/j.sbspro.2015.07.263

Gust, H., Krumnack, U., Kühnberger, K., \& Schwering, A. (2008). Analogical Reasoning: A Core of Cognition. KI - Künstliche Intelligenz, 22(1), 8-12.

Hasson, U., Chen, J., \& Honey, C. J. (2015). Hierarchical process memory: Memory as an integral component of information processing. Trends in Cognitive Sciences, 19(6), 304-313. https://doi.org/10.1016/j.tics.2015.04.006

Heuer, H., \& Sanders, A. F. (2016). Perspectives on perception and action. In Perspectives on Perception and Action (Vol. 15). https://doi.org/10.4324/978131562799 
Kristayulita, K. (2021). Indirect Analogical Reasoning Components. Malikussaleh Journal of Mathematics Learning (MJML), 4(1), 13-19.

Kristayulita, K., Nusantara, T., As'Ari, A. R., \& Sa'Dijah, C. (2018). Identification of Students Errors in Solving Indirect Analogical Problems Based on Analogical Reasoning Components. Journal of Physics: Conference Series, 1028(1). https://doi.org/10.1088/1742-6596/1028/1/012154

Kristayulita, Kristayulita, Asari, A. R., \& Sa'dijah, C. (2017). Masalah Analogi: Kajian Teoritik Skema Penalaran Analogi. Jurnal Ilmiah MIPA, 1(1), 435-441. http://conferences.uin-malang.ac.id/index.php/SIMANIS

Kristayulita, Kristayulita, Nusantara, T., As'ari, A. R., \& Sa'dijah, C. (2020). Schema of analogical reasoning-thinking process in example analogies problem. Eurasian Journal of Educational Research, 2020(88), 87-104. https://doi.org/10.14689/ejer.2020.88.4

Kristayulita, Nusantara, T., As'ari, A. R., \& Sa'dijah, C. (2019). Tahapan Penalaran Analogi dalam Menyelesaikan Masalah Analogi Indirect. Prosiding Seminar Nasional, 3(1), 437-443.

Orgill, M., \& Bodner, G. M. (2006). An analysis of the effectiveness of analogy use in college-level biochemistry textbooks. Journal of Research in Science Teaching, 43(10), 1040-1060. https://doi.org/10.1002/tea.20129

Panjaitan, B. (2013). Proses Kognitif Siswa Dalam Pemecahan Masalah Matematika. Jurnal Ilmu Pendidikan, 19(1), 17-25.

Polya, G. (2004). How to solve it: A new aspect of mathematical method. Princeton university press.

Purcell, E., Varberg, D., \& Steven, E. R. (2010). Calculus (9rd Edition) - Dale Varberg, Edwin Purcell and Steve Rigdon.pdf (pp. 215-243).

Reheat, A. (2014). Model Pembelajaran Pemrosesan Informasi. Jurnal Pendidikan Ilmu Sosial, 23(2), 1-10.

Ruggiero, \& Vincent, R. (2011). Beyond Feelings: A guide to Critical Thinking. New York: Mc Graw Hill.

Ruppert, M. (2013). Ways of Analogical Reasoning - Thought Processes in an Example Based Learning Environment. Eight Congress of European Research in Mathematics Education (CERME 8), 6-10.

Santrock, J. W. (2009). Psikologi Pendidikan: Educational Psychology. Salemba Humanika 86.

Slavin, R. E. (2006). Educational Psychology Theory and Practice. Washington DC: Pearson.

Slavin, R. E. (2008). Psikologi pendidikan: Teori dan Praktik edisi kedelapan (Jilid 1). PT Indeks.

Solso, R. L., Maclin, O. H., \& Maclin, M. K. (2008). Psikologi kognitif. Erlangga.

Solso, Robert L., MacLin, M. K., \& MacLin, O. H. (2005). Cognitive psychology (7th ed.). Pearson Education New Zealand.

Sternberg, R. J. (1977). Component processes in analogical reasoning. Psychological Review, 84(4), 353-378. https://doi.org/10.1037/0033-295X.84.4.353

Sukoriyanto, S. (2018). Utilization of Information Processing Theory to Identify Studentsr Thinking Interference of Global Type in Solving Permutation Problems. 218(ICoMSE 2017), 217-220. https://doi.org/10.2991/icomse-17.2018.38

Trench, M., Oberholzer, N., \& Minervino, R. (2009). Dissolving the analogical paradox: Retrieval under a production paradigm is highly constrained by superficial similarity. Conference on Analogy, 1-10. http://www.nbu.bg/cogs/analogy09/proceedings/47T43.pdf

Vidulich, M. A., Wickens, C. D., Tsang, P. S., \& Flach, J. M. (2010). Information Processing in Aviation. Human Factors in Aviation, December, 175-215. https://doi.org/10.1016/B978-0-12-374518-7.00007-9 
Wickens, C. D. (1991). Processing Resources in Attention. Multiple-Task Performance, 61.

Wijaya, A., van den Heuvel-Panhuizen, M., Doorman, M., \& Robitzsch, A. (2014). Difficulties in solving context-based PISA mathematics tasks: An analysis of students' errors. Mathematics Enthusiast, 11(3), 555-584.

Wolfe, J. M., \& Horowitz, T. S. (2017). Five factors that guide attention in visual search. Nature Human Behaviour, 1(3), 1-8. https://doi.org/10.1038/s41562-017-0058 